\title{
Cycling through the World Wide Web
}

As the use of the web increases for leisure activities, so does its use as a second textbook for academics. Already the web is full of sites dedicated to cell biologists, fly geneticists and Caenorhabditis elegans enthusiasts (to name but a few). Today, even individual laboratories are generating their own home pages to show the world their research, their results and, more often than not, their beautiful images. The aim of this small review is to highlight a few websites that cover research on the cell cycle and cell division. This is not meant to be a comprehensive list of sites, or to highlight those that are necessarily the best, but these are just a few personal favourites that cover a wide range of topics.

\section{General cell-cycle and cell-division websites}

These sites are often run by large organizations or scientific institutions. Their aim is to promote general areas of cell-cycle research and to provide links to primary research papers and more specialized sites.

http://www.biology.arizona.edu/cell_bio/tutorials/cell_cycle A good, comprehensive overview of the cell cycle with useful links. Includes great diagrams and problem-solving exercises.

http://www.mailbase.ac.uk/lists-a-e/cell-cycle/ M ailbase list dedicated to cell-cycle biology.

http://vl.bwh.harvard.edu/

Virtual library of cell biology with links to the cell cycle and cytokinesis.

\section{http://www.stke.org}

Website run by Science for general links to signal transduction and the cell cycle.

\section{http://www.sdsc.edu/kinases/}

Website focusing on protein kinases which highlights those that are important in the cell cycle and cell division.

http://www.nature.com/ncb/celldivision

This site is a special website with access to the Focus on Cell Division issues of both Nature Cell Biology and Nature Reviews Molecular Cell Biology.

\section{Organism-specific cell-cycle and cell-division websites}

Most of us who are involved in research have our own particular favourite organism. Here we highlight a few that may be useful to those working with yeast or flies.

http://cellcycle-www.stanford.edu

Yeast-specific site with many links. Not much raw information but plenty of places to go and find it.

\section{http://sdb.bio.purdue.edu/fly/aignfam/cellcycl.htm}

An interactive fly site with information on every known D rosophila cell-cycle gene. Good links to related references. http://flybase.bio.indiana.edu/

The bible for fly geneticists and fly cell biologists. Information is provided on all known Drosophila genes, but there are no specific links for the cell-cycle researcher.

http://elegans.swmed.edu/

Nematode-specific website, which can tell you anything you ever wanted to know about $\mathrm{C}$. elegans. However, none of its content is specific to the cell cycle.

\section{Molecule-specific websites}

http://www.blocks.fhcrc.org/ kinesin

Excellent website focusing on kinesin. There are links to great movies, all the background knowledge you would ever need, and information on kinesin-related proteins. Recent publications are also highlighted. Throughout this site there are also links to the myosin homepage.

http://www.mrc-Imb.cam.ac.uk/myosin/myosin.html

Run by Dr. J. Kendrick-Jones from the M RC-LMB (Cambridge, UK), this site is constantly updated to highlight the recent advances in the field and provides many links to myosin databases.

\section{Lab-specific cell-cycle and cell-division websites}

http://www.unc.edu/depts/salmlab/mitosis/mitosislabs.html Website run by the laboratory of Dr E. Salmon (Univ. North Carolina). Contains links to all the individual home pages and main journals in the field you could ever ask for. There are also great movies.

\section{http://www.wadsworth.org/BM S/SCBlinks/WEB_M IT2/}

HOME.HTM

Dr. C. Rieder's (Wadsworth Center, Albany) personal website, which has beautiful pictures and some handy hints on the tools used to generate them.

http://mcdb.colorado.edu/labs/winey/databases.html

Great for links on Saccharomyces cerevisiae, especially the Saccharomyces Genome D atabase (SGD).

\section{New for 2001}

http://biomedcentral.com/nspprimers/

http://new-science-press.com/primers.asp

See this website for the early chapters of David M organ's new book entitled The Cell Cycle published by New Science Press.

http://www.blacksci.co.uk

In January 2001 Blackwell Science will publish a new book entitled Cell Cycle Biology by F. M onette. Please see website for details. 